\title{
Planning services for the elderly
}

\author{
Greg Spencer \& David Jolley
}

\begin{abstract}
"The psychiatric aspects of ageing are a major problem in any country which, like our own, has a low net reproduction rate and a high standard of social responsibility. The proportion of old people in the community steadily increases so that they provide an increasingly high proportion of our mentally infirm who must be cared for".
\end{abstract}

This appraisal of the need for specialist services for the elderly comes not from a recent Royal College of Psychiatrists consensus statement, nor even from a trust mission statement, but from the late Professor Sir Aubrey Lewis speaking to the Royal MedicoPsychological Association in 1945.

Lewis was speaking at a time when there were no effective treatments for the major serious psychiatric syndromes and 'responsibility' meant informed and humane care of a passive nature. A time too, when mental health provision came from an asylum system set apart from the mainstream of general medical services and welfare facilities available to ordinary citizens (Jones \& Sidebottom, 1962). Only 9.6\% (4.3 million) of England's population were aged 65 years or more (2.7 million over 75 ) compared with $15.6 \%$ ( 9 million) aged over 65 years ( 6 million over 75) expected in 2001.

He might be surprised and pleased to discover what has happened during the half century which has followed. Fairly effective treatments for the 'functional' psychoses have reduced the cumulative morbidity associated with schizophrenia and the major mood disorders, which previously endured into late life, as well as arising among older people. In combination with moves to integrate mental health services with general medical services and social welfare programmes, this new potency has brought psychiatry into contact with more people, promoting their well-being within their home environment, rather than their removal to passive, segregated care. This, despite the survival into their 80s and 90 s of many more people than was being predicted in the 1940s (Family Policies Studies Centre, 1991). Yet the perception persists that old age represents a 'burden' and that increased numbers of old people is a 'problem'. In part, this derives from lack of economic (wage-earning) contributions from those in retirement, in part from their physical dependency (much displaced to the later decades of late life when compared with previous generations), but largely from the unresolved threat of debility, dependency and disturbance arising from dementia.

Specialist 'geriatric' services began to be developed for physically ill and dependent old people in Britain from the late 1940s (Warren, 1946) and were followed by 'psychogeriatric' services from the late 1960s (Arie, 1970). These 'specialist' or secondary health care developments have found themselves maturing within the context of health and welfare programmes, which have changed progressively in response to medical and public health advances, the size and age structure of the population, availability of funds, political will and expediency and management fashions. They no longer restrict their interests and activities to caring for the rump of pathology declared too difficult by other agencies. They must plan and deliver with other agencies across a spectrum of education, recruitment, training and support, audit, research and development in prevention, treatment and rehabilitation, as well as continuing (terminal) care.

Greg Spencer is a Senior Registrar in Old Age Psychiatry at the Blakenhall Day Resource Centre (Haggar Street, Wolverhampton WV4 5HN). His special interests include the history of psychiatry, with special regard to service development and provision. David Jolley is Professor of Old Age Psychiatry at Penn Hospital (Wolverhampton WV4 5HN). He is Medical Director of Wolverhampton Health Care NHS Trust. He pioneered the development of old age psychiatry services in the northwest of England and has continued to develop and evaluate services, and encourage and support others in this work over a period of 25 years. 


\section{Planning}

\section{Overview}

The discipline of first establishing Where are we now?' followed by 'Where do we want to get to?' and a consideration of 'How are we going to get there?' underpins all approaches to rational developments for the future (see Fig. 1).

\section{Working group}

Planning has to be a shared activity with contributions drawn from interested and responsible parties, sometimes styled stakeholders (Royal College

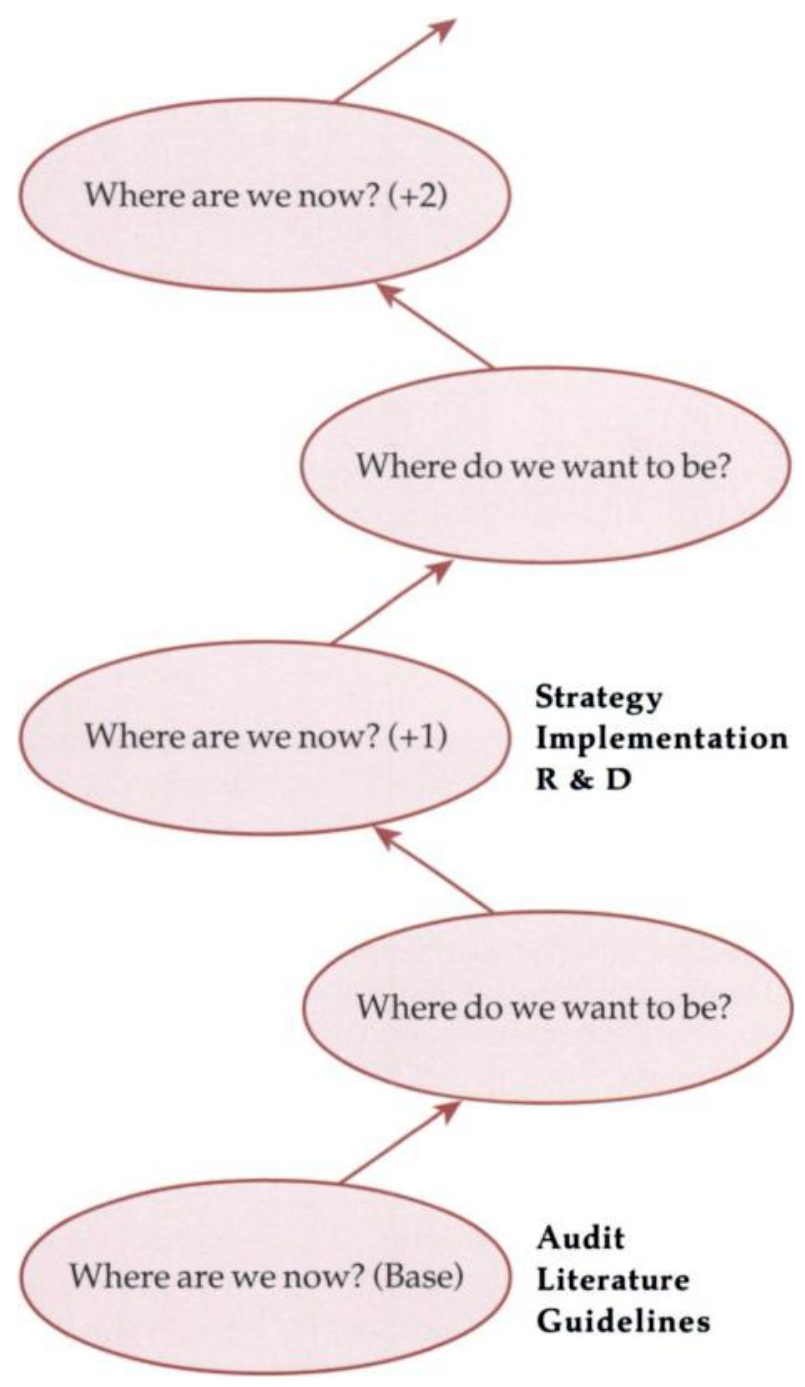

lig. I The plomning -piral of Psychiatrists \& Faculty of Public Health Medicine of the Royal College of Physicians of the UK, 1993).

The group must agree a remit - and 'services for older people with mental illness' or something similar is a reasonable working title - but this will require clarification, in particular, the population to be serviced, defined by geography or association with a particular facility or group of facilities. Thus, we might be interested in the population for which a health authority is responsible - receiving services from one or several National Health Service (NHS) trusts and overlapping with one or several local authorities; or the catchment population of a single NHS trust servicing one or more health authority populations/one or more local authority populations. We are about to explore the advantages of primary care groups, which have attributes of both geography and service dynamics (and offer another possible planning forum).

The chairmanship and lead responsibility for the planning forum will be determined by its origins and remit, though membership of the group may be similar, whatever/whoever is driving the process.

Representatives of those responsible for commissioning (purchasing) services

Health authorities, local authorities, primary care groups.

Those responsible for delivering services directly or indirectly

National Health Service trusts, local authorities, social services, housing and other organisations, general practitioners (GPs), community health council(s), voluntary organisations in the field (Alzheimer's Disease Society, Age Concern), 'users' or their representatives, and carers.

In addition, relevant professions must be able to contribute either by membership of the main group or by attendance on request - psychiatrists, geriatricians and other specialists, nurses, paramedics, social workers, psychologists and religious leaders and/or spokespersons for minority groups. Educationalists may be included and are likely to contribute very positively.

\section{Relationships}

Old age psychiatry may find itself managed within the orbit of mental health as in most NHS trust arrangements - or within 'care of the elderly' favoured by local authorities and (it is rumoured) the national frameworks. Thus, its planning may be conducted as part of the spectrum of mental health services or elderly care services. Whichever, it is 
important that the process is informed by what is occurring and planned for the sister 'discipline', and that the sister discipline is informed and able to comment on/influence the activities of this working group.

\section{Strategy and implementation}

In designing its work, the group will agree to produce a strategy document which will be offered to public consultation and revised before being owned by the initiator organisation and contributors. This strategy can then guide the activities of implementation groups addressing particular aspects of the development.

\section{Aims and objectives}

It is likely that the group will begin with a general idea of what it wants to do: to provide a decent service for older people with mental illness. This aim needs to be reduced to practical objectives based on clear definitions and the best information available. Thus, mental illness in late life includes a number of syndromes: dementia, delirium, mood disorders, paranoid disorders, adjustment reactions and others. All have differing characteristics, aetiologies, prognoses and needs for their appropriate assessment, treatment, after-care and prevention.

Prevalence and incidence studies from the literature - particularly from areas similar to that under consideration - will be helpful, but might be supplemented by local data to clarify the scale of the work required and how far present services are meeting predicted needs and demands. The latter can be estimated by rates of referral, speed of response, waiting lists and/or the presence of blocked beds. Surveys of user satisfaction and audit of practices and outcomes add further refinement to an understanding of adequacy. Focus groups of users, carers and professionals can help identify areas of need or potential opportunities, which are otherwise hidden.

When these considerations suggest that change in the shape or capacity of service components is needed, reconsideration of capital and revenue resources becomes essential. Often a good deal can be achieved by re-channelling limited resources into new ventures and reducing dependence on other, longer-established practices. It is likely that some expansion of financial allocation will be required in most areas since the number of older people with mental illness is increasing, and the demand for improved quality of care is undeniable.

\section{The population}

The number and percentage of old and very old people differs between electoral wards and it is important to have an eye for the availability of care from the middle generations, especially women, taking account of potential alternative calls upon their time from children and employment.

It may be possible to calculate likely changes in the population over 10-20 years. Such calculations depend upon knowledge of the numbers and life expectancy of people in the population in middle age and the likelihood of their movement out of (or into) the target area.

There is considerable interest in the differential use of services by elders from ethnic minority groups (Abraham \& Hiller, 1991). Most immigrant groups including Asians and African-Caribbeans currently include only about $5 \%$ of over-65-year-olds (compared with $14-15 \%$ in the White indigenous population). This is a function of internal population dynamics including life expectancy. In addition, there continues to be a flow to and from the base countries of older people who are moving to receive care from other members of the family. A knowledge of numbers, dynamics and particulars of requirement is a necessary aid to planning.

Social class, as determined by employment (including previous employment) of the head of household, is a predictor of disability (greater in social classes IV and V) and the availability of resources to purchase help (greater in social classes I and II) (Office of Population Censuses and Surveys, 1988).

\section{Facilities}

Quality, nature and distribution of the housing stock influence the ease with which people can be maintained at home.

While familiarity with the environment is probably the greatest help when memory fails and dementia supervenes, proximity to caring members of family and the availability of central heating, easy access and other conveniences certainly strengthen any care package.

Owner-occupiers may be reluctant to leave a favoured family home, but may decide to release capital and invest in a smaller, easier property.

Rental from local councils has become less available of late, but is still used by many older people. Facilities have generally been upgraded (making care at home easier), but old people may be encouraged to move to 'sheltered' schemes. This releases domestic accommodation for younger families, and brings the advantages and safety of 
communal life to older people. An interesting range of sheltered or retirement complexes is being developed and some offer graded support in-house, designed to help people remain at home unless in need of acute hospital care. The strengths of the housing infrastructure and the personal attributes of those living within it will greatly influence the need to use other forms of accommodation.

Residential homes still accommodate the majority of older people who give up their private residential status. The 1980s and 1990s saw a shift of emphasis from local authority to private ownership. Standards for accommodation have been improved, although quality and supervision of staffing is less certain (Joseph Rowntree Foundation Inquiry, 1996). Private sector homes are probably less prepared/ able to accept or retain disabled residents, particularly when confused. Their share of the market may be reducing; eroded at one end by very sheltered housing schemes and at the other by competition from nursing homes. One factor keeping them in business is their relative cheapness - certainly a consideration for social services in their role as purchasers of care.

Nursing homes are big business. With the enclave of the self-sponsoring well-to-do in the 1970 s and early 1980s, they increased in number, capacity and distribution as a result of placements using social security benefits (now perpetuated through social service purchasers) (Joseph Rowntree Foundation Inquiry, 1996). Many are owned by large organisations. They may offer specialist 'EMI' or 'mental nursing' care and have been encouraged as preferable alternatives to outdated long-stay hospital care (shifting expenditure from health authorities to individuals or social security, and later, social service budgets). They have maintained their impetus because residential homes have found it less attractive to retain or accept 'problem' residents requiring additional or more skilful care.

Hospitals used to provide long-term care for the chronic sick elderly either in mental hospitals or in 'geriatric hospitals' - with both institutions including a mix of physically and mentally impaired patients (McKeown \& Lowe, 1961). The buildings used were often ill-sited and poorly appointed, staffing levels and skills being limited. In most localities, this accommodation has disappeared or been greatly improved. The importance of retaining a ration of long-stay care beds of nursing home proportions within the hospital service, preferably within NHS units, has been accepted (House of Commons Health Committee, 1995).

The majority of hospital activity is, however, of the 'acute' or rehabilitation variety. In general hospitals there is a range of specialities, all of which see large numbers of elderly patients, as well as the special elder care facilities of geriatric medicine and old age psychiatry (Royal College of Physicians, 1994).

Care away from home on a day-to-day basis has evolved as a component of both social support and health care, offering assessment, treatment and rehabilitation without requiring the patient to give up his or her own bed (Jolley, 1994).

\section{Support at home}

The $94 \%$ of older people living at home turn first to family and then to others when they need help. Fortyeight per cent of over $65 \mathrm{~s}$ and $14 \%$ of women over 80 live with another old person (spouse or sibling), $8 \%$ of over $65 \mathrm{~s}$ and $23 \%$ of women over 80 live with younger people (daughter, sons or others), but $36 \%$ of over $65 \mathrm{~s}$ and $61 \%$ of over 80 s live alone and so are at the greatest risk when unwell or disabled (Family Policie Studies Centre, 1991).

The first requirement is that they, or someone they trust, recognise that something is going wrong and have the information to turn to an appropriate source to obtain help. Help may include assessment and effective treatment for an illness through a GP, with or without help from a specialist. It is likely that supplementary help in the form of 'social care' or 'nursing care' will be necessary in the short or long term. Such care may be purchased directly by the old person or her family, or by social services (who may turn to independent (private) agencies to supply the care, or provide it directly, or within the NHS (district nursing, community psychiatric nursing)).

This is the world within which older people live and experience emotional problems, memory difficulties or mental health problems. It is the framework against which services for older people with mental illnesses must be structured and must function and be evaluated. A sophisticated planning process would establish the prevalence of mental disorders in older people, and the needs met and unmet by currently available services. The gap between needs identified and needs met determines the change to be achieved between 'Where are we now?' and 'Where do we want to get to?', and it also supplies the 'Why'?

But to determine 'needs arising' is a massive task, if it is to be undertaken with scientific rigour based on collected data. In practice, most planning groups will take soundings from around the table and beyond, underpinned as far as possible by facts derived from routinely available data. In addition, the local pattern of provision and activity will be compared with national averages and guidelines 
on good practice issued by professional groups or the NHS Executive.

\section{Core business}

The core business of old age psychiatry - reaching out to people with the most severe and complicated illnesses and offering appropriate assessment, treatment and after-care - has evolved on the basis of historical patterns of resource, interpreted and modified by pioneer enthusiasts and confirmed in outline by guidance from the Department of Health and Social Security in the 1970s, which has been upgraded in some detail by the Royal College of Psychiatrists, either alone or in conjunction with the Royal College of Physicians, the British Geriatrics Society or the Royal College of Nursing (Royal College of Physicians \& Royal College of Psychiatrists, 1999).

\section{Beds}

Guidance includes suggestions on the bed complement and distribution for a service catering for 30000 people aged over 65 years (see Boxes 1 and 2). This is helpful because these are the most expensive elements of the service (capital and revenue) although they are needed by relatively few patients. There is no evidence base to these numbers, if evidence is defined as information derived from randomised trials of different numbers and arrangements of beds. The guidance derives from

Box 1. Features of a typical old age psychiatry service (summarised from Arie \& Jolley, 1998)

Initial domiciliary assessments

Multi-disciplinary teamwork

Above all, a community focus

Acute beds for functional and organic illness in an admission unit

Longer-stay beds in continuing care units

Well-staffed day hospital places

Liaison with primary care

Liaison with geriatric medicine

Liaison with other medical specialties

Liaison with social services

A working relationship with the private sector
Box 2. Guidelines for a district service for 30000 elderly people (Royal College of Physicians \& Royal College of Psychiatrists, 1999)

Acute beds $45-60$

(functional and organic)

Continuing Care beds $\quad 75-90$

Day hospital places $\quad 75-90$

Consultants $\quad 1.5-3$ WTE* $^{*}$

Secretaries 1.5-3 (plus

day hospital clerical time)

Community psychiatric nurses 6

Occupational therapists 3

Physiotherapists $\quad 1.5$

Clinical psychologists $\quad 1.5$

${ }^{*}$ Whole-time equivalents

experience in practice, shared by professionals over the past 30 years.

Siting and configuration of acute beds may be adjusted to local taste and convenience: for example, district general hospital; community hospital with general psychiatry or geriatric medicine; specialist wards for organic/functional disorders; or mixed wards available to particular communities.

Given the severity and complexity of problems, wards should not contain more than 20-24 patients (as a rule of thumb). A similar (size) consideration applies to continuing care/long-stay units, whose very existence was the subject of fierce contest eventually won (Section for Psychiatry of Old Age, 1991; House of Commons Health Committee, 1995). Few practitioners feel that anything other than a directly managed, devoted unit obtains the best use from this provision, particularly when it includes 'respite' and day hospital options. The alternative of purchasing individual beds within nursing homes can lead to loss of impact and repeated debates over equity.

Continuing care NHS beds for older people with mental illnesses are almost all devoted to the care of people with severe dementia. They are one end of the spectrum of resources which begins with care at home, through residential care (registered and regulated by the local authority and perhaps replaced in part by sheltered housing) and nursing homes (regulated by the health authority and including specialist EMI units). As such, the need for them and demands upon them will vary with the capacity, competence, balance and distribution of other 
elements of the spectrum - all to be taken into account in planning and re-modelling (Benbow et al, 1994).

\section{Day hospitals}

The National Audit Office (1992) recognised over 600 day hospitals in England providing geriatric and psychogeriatric care, offering 16000 places each weekday at a cost of $£ 125$ million per year. Widespread establishment came about following explicit support from the Department of Health and Social Services. Aided by central NHS funding, the country became "dotted with a network of spacious, relatively modern buildings - suitable for accommodating large numbers of patients every day staffed with a full team of health professionals but often used only between the hours of $10 \mathrm{am}$ and 4 pm Monday to Friday" (Murphy, 1994).

Yet the logic behind the day hospital movement and evidence for its effectiveness is still debated (Howard, 1994; Fasey, 1994). Do day hospitals succeed as an alternative to in-patient admission or in facilitating a better assessment than can be achieved at home? Do they offer better carer support, rehabilitation and maintenance of community links than local authority, voluntary sector or private sector day care? Do they delay or obviate entry into long-term residential care?

In our service in the West Midlands, we have found the presence of a day care facility invaluable. Whether in the form of a traditional day hospital or a day resource centre shared with the local authority, it is a welcomed integral part of the locality-based service. The size and spaciousness of such facilities can be economically and efficiently used; their rooms are ideal for small group activities, medical suites or memory clinics. A walk around spacious grounds is a useful management strategy for the restless, agitated patient. Identification as a team base and point of contact for patients, carers and colleagues puts it firmly at the hub of the service. Carers' support and education groups held in the evenings and at weekends mean that there is more time in the week when the building can give active and valued service.

\section{Out-patient clinics}

Traditional hospital-based clinics may make good use of expert staff at least for some aspects of assessment (Jolley \& Arie, 1992) where they may replace the need for admission or attendance of day hospitals. Alternative bases - resource centres, GP clinics or the patient's own home-are preferred for more routine contacts.

\section{Community mental health teams for the elderly}

With consultants, secretaries, community psychiatric nurses and social workers taken to be essential components, community mental health teams may include a range of other professional skills occupational therapy, physiotherapy, clinical psychology, speech therapy, chiropody, clinical pharmacy - all enriching the service. Their team base may be in association with an in-patient unit, day hospital/resource centre or elsewhere for ease of access for the population served. The team's activity turns the anatomy of facilities into the physiology of the service - being available, initiating and continuing interventions, liaison with other agencies and making things work for individuals and groups. Taking all these responsibilities into account, and modifying them by consideration of geography and the organisational units of sister services, most teams will find a target population of about 10000 older people appropriate. Most teams accommodate systems which allow GPs direct access to some of their non-medical professionals: some teams encourage 'open access' to all the team's activities and some organise initial assessments by any one of a number of professionals, but most retain a mainstream of referrals from GPs or other doctors to the team. Initial assessment occurs within a matter of hours or days by the consultant or another senior doctor at the patient's home or bedside (Herzberg, 1995; Jolley et al, 1998). Particular models may be better suited for dispersed populations (Tym et al 1991). Regular reviews with the local social service team are routine in most services, and individual general practices benefit from a designated linkworker from within the team. Regular review of known patients in nursing homes and residential homes is at least as important as similar support and monitoring of patients still maintained at home.

Liaison with colleagues in geriatric medicine and other specialities is very well organised in some services, but with the reorientation of geriatric medicine towards medicine of old age and reintegration with general medicine the logistics of such work has become more difficult. This phenomenon has challenged old age psychiatry to develop more comprehensive models of liaison with general hospitals, perhaps looking to a sub-speciality activity, liaison psychiatry.

\section{The needs of carers}

There is increasing literature on the difficulties faced by the carers of the elderly, particularly those with 
dementia. Saad et al (1995) explored the coping strategies used by carers of people with dementia and found that active practical and psychological coping mechanisms benefited those who used them and had an important inverse relationship with the prevalence of carer depression. It follows logically that 'active practical and psychological coping mechanisms' are built on a foundation of knowledge of the nature of the problems faced and the confidence to use that knowledge effectively. Graham et al (1997) found that carers with a lower overall knowledge of dementia feared 'not being able to cope'. Contact with an Alzheimer's disease support group increased knowledge and reduced carer burden.

This emphasises the importance of a close liaison with carers, both directly and through organisations such as Age Concern and the Alzheimer's Disease Society. These bodies not only do an enormous amount to publicise the needs of carers, but also offer practical support and information. Informal carers' groups, meeting either under the umbrella of voluntary services or through the day hospital, can provide a forum for swapping practical tips learned through personal experience, and for sharing problems and allowing the carer to feel part of a cohesive group, rather than someone isolated in despair.

Old age psychiatrists and other team members will find themselves welcome at seminars, lectures and open days organised by the Alzheimer's Disease Society and other groups. Links forged in this manner will add further strength to the service.

\section{Target population}

\section{Age}

'Older people with mental illness' is an umbrella term which requires clarification for practical planning purposes. 'Older' has often been assumed

Box 3. Subjects of special interest

Day hospitals: what is their role?

Needs of carers: are they being recognised?

Pre-senile dementia: a place for specialist services?

Graduates: who should be responsible?

New treatments for dementia: determining best practice to be 65 years and above within NHS circles; it may be increased to 75 years or some other convenient cut-off point for practical reasons - usually based on the balance of manpower and perhaps other resources available locally. Consideration needs to be given to the contribution within functional disorders from the old age service on the one hand and general psychiatry on the other - and to the management of dementia in the pre-senium.

\section{Functional disorders}

Most old age services will wish to take on all patients presenting with mood disorders and other 'functional' conditions within late life. This has to be agreed and resources appropriate to the responsibility made available.

Less clear-cut is the approach to people growing old with continued or relapsing illness. Many patients (and their families and GPs) prefer that an established relationship with a general psychiatrist or community mental health team continues despite the arrival of their 65th birthday. This needs to be accepted and given weight in both planning and practice. Yet the allocation and management of resources within the NHS and local authority, together with the turnover of staff (community psychiatric nurse moves to another post, consultant retires) increasingly makes such flexibility a marginal phenomenon.

Graduates - those patients who entered hospitals for the mentally ill before modern methods of treatment were available and have grown old in them - have not remained in hospitals in the numbers predicted by Tooth \& Brooke (1961), but similarly damaged people exist and are in touch with services for either the mentally ill or the elderly. Some have become neglected and have fallen out of touch with services, and many require reappraisal of their mental, physical and social needs. It is important that they are identified by local survey and registration, and that agreement is reached on who will be responsible for their ongoing treatment and support. They are likely to have fewer positive psychiatric symptoms than in the past, but negative symptoms and side-effects from medication may be problematic (Campbell, 1991). Their physical health is often poor and their mortality remains elevated (Baxter, 1996).

\section{Organic disorders: delirium and dementia}

Although psychiatrists have a role in the assessment and management of 'acute confusional states' / 
delirium (Byrne, 1994), this is limited and has not attracted systematic interest. People presenting with such syndromes are usually best cared for in a medical setting so that identification and treatment of underlying causes can be addressed competently. This is often a fairly straightforward task and appropriate treatment (or death) terminates the mental disorder and associated behavioural problems quite quickly. Even so, management problems in the short term may be very difficult putting the patient, other patients and staff at risk. There are sometimes problems, especially when the underlying condition is complex, obscure or untreatable.

An operational policy for management and responsibilities is essential. Most hospitals will find this an area where matters could be improved.

Responsibility for dementia is the central activity of old age psychiatry. Yet dementia is so common, and the needs of patients and families so multifaceted, that the specialist service contributes only a part of what is needed at any point in time. There is little disagreement, however, that they should offer a coordinating and supportive follow-through service to most older people with dementia (Arie \& Jolley, 1998).

\section{Pre-senile dementia}

Dementia in the pre-senium is a comparative rarity - pre-senile dementia of Alzheimer type (the most common type) accounting for 20 sufferers per 60000 people aged 45-64 in one English health region (Newens et al, 1993). The nature of the dementias is diverse including sporadic conditions (Alzheimer's disease, Parkinson's disease, etc.) and acquired dementia (cerebrovascular disease, brain trauma, alcoholic brain damage). Thus, some syndromes are inherited - and the rapidly increasing knowledge base of genetics and chromosome mapping means that individuals and families should become known to a relevant genetics department (Wilson \& Ferran, 1996) - others are acquired, and most should be investigated in association with departments of neurology and radiology equipped to define and interpret underlying pathology (Allen \& Baldwin, 1995). Needs are often not being recognised or met, largely through a lack of knowledge of who the patients are, where they are and what is currently happening with them.

The effects of a dementia on a person who is still a family breadwinner, parent of young children or main carer of an elderly relative can be devastating and require special consideration. Delany \& Rosenvinge (1995) discovered a high level of cognitive, behavioural and self-care difficulties together with substantial carer stress among patients and families in Southampton. Current problems are summarised in Box 4, and a report is in preparation by the Faculty of Old Age Psychiatry at the Royal College of Psychiatrists that argues for the provision of specialist services - each covering a large population area - with a consultant old age psychiatrist contributing protected sessions to the work of a multi-disciplinary team (further details available from the second author upon request).

\section{Memory clinics}

Although it has been accepted good practice that a thorough search for treatable components to a dementia syndrome be pursued and followed by careful clinical monitoring (Pitt, 1998), the more detailed investigation of milder cases and monitoring through multi-axial measurements associated with 'memory clinics' has been regarded as a research activity or luxury available only in centres of excellence (Wright \& Lindesay, 1995). This position is changing as interest and knowledge of dementia become widespread and expectations, backed up by the potential for complaints and litigation, drive up standards. The licensing of 'rational' treatments for Alzheimer's disease and the need to channel their usage toward people who benefit from them increases the argument for a memory clinic as a component of every specialist service. This will be a new venture in most places and carries considerable cost implications over and beyond the cost of medication (Rogers et al, 1998; Working Group for the Section of the Psychiatry of Old Age, 1997).

Box 4. Recognised difficulties in providing a service for individuals with pre-senile dementia

General adult psychiatry has little experience with dementia

Services for the elderly are often inappropriate

Most purchasers have difficulty finding an appropriate service

There are few genetic counselling services

Neurological or neuroradiological and psychological support are vital 


\section{New horizons - wider responsibilities}

The further development of the NHS reflected in the series of White and Green papers emanating from the New Labour Government (Department of Health, 1997a, 1997b, 1998) encapsulates current expectations.

\section{Quality}

Quality (including safety) must be ensured and progressively improved.

\section{Education}

Education is to be made more widely available for the benefit of the lay public, patients and carers and to professionals of all disciplines and grades throughout their careers.

\section{Preventive approaches}

Preventive aproaches must be explored, avoid the development of ill-health where at all possible and promoting good health by healthy living. Failing that, one must limit the damage arising from illness by early identification and treatment, rehabilitation and maintenance strategies that are aggressively available, and take into account all aspects of the patient's welfare, including that of the carers and dependants.

These represent major new challenges and it is extremely helpful that they have been identified by government policy. This requires each health authority, primary care group, National Health Service trust, and related agencies, to identify what they are currently offering in these areas. In most instances, this is very little. Then it is necessary to review what is known and what can be done, and find the resources to do it.

This exercise in these new areas of responsibility, as with the longer-established 'service' delivery, requires the use of audit, supported and extended by research and development to inform the feed-back loop of the planning cycle-or rather, the planning spiral - progressively raising levels of achievement.

\section{Summary}

Charcot, the Napoleon of neurology, gave some of his first lectures on diseases of the elderly. He has been quoted thus: "...senile pathology too has its difficulties... And yet this very interesting part of medicine has long been neglected, and hardly in our own days has it succeeded in gaining its independence" (Howell, 1988).

The care of elderly people with mental illness, has won for itself not just independence, but also respect and a place at the top-table of an innovative and expanding health and social care system. As existing services change and experiment with new ideas, and as new services come into being, the need for rational and meaningful planning is paramount. The principles outlined here have a general applicability, have stood the test of time in usage over four decades and will serve the future well.

\section{References}

Abraham, S. \& Hiller, S. (1991) Ethnic minority needs. Reviews in Clinical Gerontology, 1, 195-199.

Allen, H. \& Baldwin, B. (1995) The referral investigation and diagnoses of presenile dementias. Two services compared. International Journal of Geriatric Psychiatry, 10, 185-190.

Arie, T. (1970) The first year of the Goodmayes Psychiatric Services for old people. Lancet, $i i, 1179-1182$.

_ \& Jolley D. (1982) Making services work. Organisation and style of psychogeriatric services. In The Psychiatry of Late Life (eds R. Levy \& F. Post), pp. 222-251. Oxford: Blackwell Scientific.

— \& - (1998) Psychogeriatric services. In Brocklehurst's Textbook of Geriatric Medicine and Gerontology (3rd edn) (eds R. C. Tallis, H. M. Fillit \& J. C. Brocklehurst), pp. 1567-1573. Edinburgh: Churchill Livingstone.

Baxter, D. (1996) The mortality experience of individuals on the Salford psychiatric case register. British Journal of Psychiatry, 168, 772-779.

Benbow, S. M., Jolley, D. J. \& Tomerson, B. (1994) Provision of residential care for vulnerable old people. Journal of Mental Health, 3, 235-240.

Byrne, J. (1994) Confusional States in Older People. London: Edward Arnold.

Campbell, P. (1991) Graduates. In Psychiatry in the Elderly (eds R. Jacoby \& C. Oppenheimer), pp. 779-818. Oxford: Oxford Medical.

Delaney, N. \& Rosenvinge, H. (1995) Presenile dementia and sufferers, carers and services. International Journal of Geriatric Psychiatry, 10, 597-601.

Department of Health (1997a) The New NHS: Modern, Dependable ( $\mathrm{Cm}$ 3807). London: Stationery Office.

- (1997b) Developing Partnerships in Mental Health. London: Stationery Office.

- (1998) Our Healthier Nation: A Contract for Health $(\mathrm{Cm}$ 3852). London: Stationery Office.

Family Policy Studies Centre (1991) An Ageing Population (Fact Sheet 2). London: Family Policy Studies Centre.

Fasey, C. (1994) The day hospital in old age psychiatry - the case against. International Journal of Geriatric Psychiatry, 9, 519-523. 
Graham, L., Ballard, C. \& Sham, P. (1997) Carers knowledge of dementia, their coping strategies and morbidity. International Journal of Geriatric Psychiatry, 12, 931-936.

Hertzberg, J. (1995) Can multidisciplinary teams carry out competent and safe psychogeriatric assessments in the community? International Journal of Geriatric Psychiatry, 10, 173-177.

House of Commons Health Committee (1995) Long-Term Care: NHS Responsibilities for Meeting Continuing Care Needs. London: HMSO.

Howard, R. (1994) Day hospitals - the case in favour International Journal of Geriatric Psychiatry, 9, 525-529.

Howell, T. H. (1988) Charcot's lectures on senile dementia. Age and Ageing, 17, 61-62.

Jolley, D. (1994) The development of day hospitals and day care. In Principles and Practice of Geriatric Psychiatry (eds J. R. M. Copeland, M. T. Abou-Saleh \& D. G. Blazer), pp. 905-910. Chichester: John Wiley and Sons.

— \& Arie T. (1992) Developments in psychogeriatric services. In Recent Advances in Psychogeriatrics 2 (ed. T. Arie), pp. 117-135. Edinburgh: Churchill Livingstone.

-, Russell, E. \& Lennon, S. (1998) The organisation of services in geriatric psychiatry. In Principles and Practice of Geriatric Medicine (3rd edn) (ed. M. S. J. Pathy), pp. 10551068. Chichester: John Wiley and Sons.

Jones, K. \& Sidebottom, R. (1962) Mental Hospitals at Work. Henley-on-Thames: Routledge and Kegan Paul.

Joseph Rowntree Foundation Inquiry (1996) Meeting the Costs of Continuing Care. York: Joseph Rowntree Foundation.

McKeown, T. \& Lowe, C. R. (1961) The influence of age on the type of hospital to which patients are admitted. Lancet, $i$, 818-829.

Murphy, E. (1994) The day hospital debate. International Journal of Geriatric Psychiatry, 9, 517-518.

National Audit Office (1992) Hospitals for Elderly People in England. London: HMSO.

Newens, A. J., Forster, D. P. \& Kay, D. W. K (1993) Clinically diagnosed pre-senile dementia of Alzheimer type in the northern health region: ascertainment prevalence, incidence and survival. Psychological Medicine, 23, 631-644.

Office of Population Censuses and Surveys (1988) Surveys of Disability in Great Britain: Prevalence of Disability Amongst Adults. London: HMSO.

Pitt, B. (1998) Managing dementia. In Principles and Practice of Geriatric Medicine (3rd edn) (ed. M. S. J. Pathy), pp. 1069-1075. Chichester: John Wiley and Sons.

Rogers, S. L., Farlow, M. R., Doody, R. S., et al (1998) A 24week double-blind placebo-controlled trial of donepezil in patients with Alzheimer's disease. Neurology, 50, 136145.

Royal College of Physicians (1994) Ensuring Equity and Quality of Care for Elderly People. London: Royal College of Physicians.

- \& Royal College of Psychiatrists (1999) The Care of Older People with Mental Illness: Specialist Services and Medical Training (Council Report CR69). London: Royal College of Psychiatrists and Royal College of Physicians.

Royal College of Psychiatrists \& Faculty of Public Health Medicine of the Royal College of Physicians of the UK (1993) Psychiatric Services. The Report of the Joint Working Group on the Purchasing of Psychiatric Care (Council Report CR25). London: Royal College of Psychiatrists \& Faculty of Public Health Medicine of the Royal College of Physicians of the UK.

Saad, K., Hartman, J., Ballard, C., et al (1995) Coping by the carers of dementia sufferers. Age and Ageing, 24, 495-498.

Section for Psychiatry of Old Age (1991) Chaos and confusion - report of a special meeting to discuss the developments in long term care for old people with dementia. Psychiatric Bulletin, 15, 374-375.

Tooth, G. C. \& Brooke, E. M. (1961) Needs and bed trends in the mental hospital population and their effect on future planning. Lancet, $i, 710-711$.

Tym, E., Jolley, D. \& Lennon, S. (1991) Two services: a rural service in East Anglia and an urban service in South
Manchester. In Psychiatry in the Elderly (eds R. Jacoby and C. Oppenheimer), pp. 313-338. Oxford: Oxford Medical. Warren, M. W. (1946) Care of the chronic aged sick. Lancet, $i$, 841-843.

Working Group of the Section for the Psychiatry of Old Age (1997) Interim statement on anti-dementia drugs. Psychiatric Bulletin, 21, 586-587.

Wilson, K. C. M. \& Ferran, J. (1996) Services for younger sufferers with dementia. Advances in Psychiatric Treatment, 2, 258-264.

Wright, N. \& Lindesay, J. (1995) A survey of memory clinics in the British Isles. International Journal of Geriatric Psychiatry, 10, 379-385.

\section{Multiple choice questions}

1. The predicted 'elderly' population for 2001 includes:

a $10 \%$ of the population will be over 75 years

b more than $15 \%$ will be over 65 years

c $11 \%$ of 65 year olds will be 'in care'

d $60 \%$ of those over 80 and not in care live alone

e only $5 \%$ of ethnic minority populations are aged 65 years.

2. Planning for older people with mental illness is:

a something best undertaken by one organisation alone

b can be done once - and left to run its course

c has not evolved in three decades

$\mathrm{d}$ begins with a definition of the current local 'state of play'

e takes into account examples of good practice.

3. Innovations in psychiatric treatment:

a have had no impact on service needs of old people

b have reduced the number of older people coming to specialist attention

c have increased the need for education in the recognition and treatment of disorders of late life by GPs

$d$ have raised public awareness and expectations of services for older people

e have been introduced with little formal evaluation of the elderly.

4. Patients and families with dementia in the presenium:

a present with similar symptoms to older patients with dementia

b require genetic counselling

c are a homogenous group

d benefit from specialist neurological assessment

e are easily assimilated into other services for younger adults. 
5. Patients 'graduating' into old age with established psychiatric disorder:

a remain well-served by general psychiatry services

b are usually managed by social services within care of the elderly facilities

c have a higher morbidity and mortality than the general population

d have fewer florid symptoms than younger patients

e are fewer in number now than four decades ago.

MCQ answers

$\begin{array}{llllll}1 & 2 & 3 & 4 & 5\end{array}$

a F a F a F a $T$ a F

b $\begin{array}{llllllllll}T & \text { b } & \text { b } & \text { b } & \text { F } & \text { b } & T & \text { b } & T\end{array}$

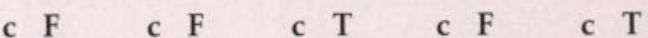

d $T$ d $T$ d d $T$ d $T$ d $\quad$ d $T$

e $T$ e $T$ e $T$ e $F$ e $F$

\section{Forthcoming from Gaskell}

\section{Evidence-Base Briefing: Dementia}

\section{Claire Palmer}

The number of published papers on the subject of dementia is constantly rising and it is virtually impossible for clinicians to read everything available, let alone to appraise it properly.

Evidence-Base Briefings (EBBs) are summarised collections of synthesised 'evidence' in a given topic area. This document on dementia attempts to encapsulate the best available evidence into a format which is quick and easy to use. Its main aim is to provide a checklist of appraised evidence from which a clinician can easily obtain original documents. These documents can then be appraised (using the tool provided) and interpreted for the clinician's own practice. The evidence sources on which the EBB is based include research, guidelines and national guidance. The EBB includes full references to its source documents and details of further information resources to support evidence-based practice.

June 1999, Paperback, ISBN 1901242358 , £15.00

Book Sales, Royal College of Psychiatrists, 17 Belgrave Square, London SW1X 8PG. Telephone +44 (0)171 2352351 ext. 146, fax +44 (0)171 2451231. Credit card orders can be taken over the telephone.

See the latest information on College publications on the Internet at:

\section{http://www.rcpsych.ac.uk}

